Please do not remove this page

RMIT

UNIVERSITY

\title{
The design and realization of uniplanar CPW fed PICA slot antennas
}

Pell, Brendan; Sulic, Edin; Rowe, Wayne; Ghorbani, Kamran; John, Sabu; Gupta, Rahul; Zhang, Kefei https://researchrepository.rmit.edu.au/esploro/outputs/9921863904401341/filesAndLinks?institution=61RMIT_INST\&index=null

Pell, B., Sulic, E., Rowe, W., Ghorbani, K., John, S., Gupta, R., \& Zhang, K. (2008). The design and realization of uniplanar CPW fed PICA slot antennas. Proceedings of the 2008 Asia-Pacific Microwave Conference, 1-4. https://doi.org/10.1109/APMC.2008.4958065

Published Version: https://doi.org/10.1109/APMC.2008.4958065

Repository homepage: https://researchrepository.rmit.edu.au

(c) 2008 IEEE. Personal use of this material is permitted. However, permission to reprint/republish this material for advertising or promotional purposes or for creating new collective works for resale or redistribution to servers or lists, or to reuse any copyrighted component of this work in other works must be obtained from the IEEE.

Downloaded On 2023/04/26 22:25:25 +1000 


\title{
The Design and Realization of Uniplanar CPW fed PICA Slot Antennas
}

\author{
Brendan Pell ${ }^{1}$, Edin Sulic ${ }^{2}$, Wayne Rowe ${ }^{1}$, Kamran Ghorbani ${ }^{1}$, Sabu John ${ }^{2}$, Rahul Gupta ${ }^{3}$, \\ Kefei Zhang ${ }^{4}$ \\ ${ }^{1}$ School of Electrical and Computer Engineering \\ ${ }^{2}$ School of Aerospace, Mechanical and Manufacturing Engineering \\ ${ }^{3}$ School of Civil, Environmental and Chemical Engineering \\ ${ }^{4}$ School of Mathematical and Geospatial Sciences \\ RMIT University, Melbourne, Australia \\ 1brendan.pell@rmit.edu.au
}

\begin{abstract}
Introduction
In modern wireless communication system design, antennas with wide impedance bandwidth are desirable for numerous reasons. An antenna with a wide impedance bandwidth may be used for transmission and reception of multiple narrowband services in a multi-purpose platform. Alternatively a single wideband service may be of interest for various radar and imaging applications, or for impulse based radio communications in the FCC Ultra-wideband (UWB) regime from $3.1 \mathrm{GHz}$ to $10.6 \mathrm{GHz}$.

Many wideband antennas are built from two-dimensional representations of threedimensional forms [1]. Cones and disk like shapes are common building blocks. When in planar form, these shapes provide impedance matching over a broad frequency range necessary for wideband antennas. The two dimensional nature of these structures lends the advantage of being planar, low-profile, easy to integrate, and inexpensive to fabricate using standard PCB techniques. Slot-type wideband antennas [2 - 4] are of particular interest because of their potential to be implemented as a single sided or uniplanar structure in which only one side of the substrate is metalized and requires processing.
\end{abstract}

Recently an antenna was presented with a very wide impedance bandwidth in excess of 10:1 [2] that is based on the Planar Inverted Cone Antenna (PICA) originally proposed by Suh et al. [3]. The antenna provides good radiation performance and high efficiency over a very wide band, yet requires double-sided fabrication due to the microstrip feed configuration.

This paper presents a new variation on existing PICA designs. The PICA is fed by coplanar waveguide, utilizing a cheap FR-4 substrate and requiring only single sided fabrication, yet maintains wideband performance.

\section{CPW fed PICA Slot Antenna Configuration}

The PICA antenna is a wideband monopole based on a unique shape proposed by Suh et al. [3]. The PICA shape is a composition of a semicircle and an equilateral triangle, with the semicircle forming the lower portion of the antenna, and the triangle forming the upper part.

In the slot adaptation of the PICA antenna, a ground plane exists which has had copper removed in the shape of a large PICA to form a slot. This slot is excited by a smaller PICA shape which extends part way into the slot. Two fundamental degrees of freedom are available for tuning the antenna performance in this geometry. They are firstly the insertion distance of the smaller exciting PICA into the larger PICA slot, and secondly the relative size of the two PICA shapes.

This research proposes a CPW fed PICA slot antenna, as depicted in Fig 1. The dimensions presented in Fig. 1 are optimized for a $0.8 \mathrm{~mm}$ thick FR-4 substrate with a relative permittivity $\varepsilon_{\mathrm{r}}=4.0$ and a loss tangent $\tan \delta=0.013$. The antenna is simulated using CST Microwave Studio utilizing the transient solver. 


\section{Simulated and Measured Performance}

The simulated and measured impedance performance of the CPW fed PICA slot antenna is presented in Fig. 2(a). According to the simulation, the antenna presents a good impedance match to a $50 \Omega$ line from $1.2 \mathrm{GHz}$ up to $15 \mathrm{GHz}$. The measured impedance response of the fabricated antenna shows a slight impedance mismatch around $13 \mathrm{GHz}$ to $15 \mathrm{GHz}$, but still obtains an impedance bandwidth of over $10: 1$ from $1.2 \mathrm{GHz}$ to $13.3 \mathrm{GHz}$. A parametric analysis of the sensitive dimensions of this design will be presented at the conference. This will hopefully indicate the reason for the discrepancy in the measured results at $13 \mathrm{GHz}$, but perhaps more importantly will also provide some design guidelines for this antenna configuration.

The simulated maximum gain of the CPW fed PICA slot antenna varies from $3.5 \mathrm{dBi}$ to 8.7 $\mathrm{dBi}$ with an average of $7 \mathrm{dBi}$ as shown in Fig. 2(b). Note that this gain is in the direction of maximum radiation, which varies depending on the frequency. The simulated and measured radiation patterns at some common communication bands are depicted in Fig. 3. These patterns display an omnidirectional like shape at low frequency (Fig. 3(a) and (b)), which becomes more directional at higher frequencies (Fig. 3(c)). Bi-directionality is evident in the $\mathrm{y}-\mathrm{z}$ plane of Fig. 3(c), as two distinct beams encroach upon endfire. There is significant correlation between measured and simulated patterns. High levels of cross polarization are evident at $\pm 45^{\circ}$ directions in the $\mathrm{X}-\mathrm{Z}$ plane, particularly at higher frequencies. This is typical of PICA slot antennas [2].

The antenna as presented comfortably provides the necessary bandwidth for UWB of 3.1 to 10.6 GHz. If such an application were desired, substrate space could be conserved by scaling the antenna. Preliminary simulations show that a scaling factor of 0.375 applied to the PICA slot would produce substrate dimensions of $45 \mathrm{~mm}$ by $45 \mathrm{~mm}$, providing impedance matching from $2.5 \mathrm{GHz}$ to $28 \mathrm{GHz}$. The simulated impulse response is shown in Fig. 4.

\section{Discussion}

The literature search revealed that a similarly structured CPW fed PICA slot antenna has been attempted previously [4], albeit with several short comings. The paper presents two adaptations of the PICA antenna, the second being closest to the geometry presented here. Despite the similarities, the antenna design in [4] uses a grounded coplanar waveguide, necessitating double-sided fabrication techniques, and has a substantially different shaped slot. Although the substrate dimensions and material used are almost identical, the antenna in [4] has a narrower bandwidth: the impedance bandwidth starts at around $3 \mathrm{GHz}$, and the return loss results reveal a further mismatch near $5 \mathrm{GHz}$. Our design provides over an octave of additional bandwidth, with a well matched response down to approximately $1.2 \mathrm{GHz}$.

\section{Conclusion}

A CPW fed slot antenna has been presented which is based on the Planar Inverted Cone Antenna. The PICA's wide impedance bandwidth behavior has been preserved, demonstrating impedance bandwidth in excess of 10:1. Omnidirectional radiation is exhibited at the lower end of the impedance bandwith. Notably, the CPW fed PICA slot antenna presented here is truly uniplanar requiring only single sided substrate processing. Uniplanar antennas can be extremely advantageous in certain applications. 


\section{References}

[1] H. Schantz, The Art and Science of Ultra-Wideband Antennas, Artech House Publishers, 2005 , pp. 228.

[2] Shi Cheng, P. Hallbjorner, and A. Rydberg, "Printed Slot Planar Inverted Cone Antenna for Ultrawideband Applications," IEEE Antennas and Wireless Propagation Letters, vol. 7, 2008, pp. 18-21.

[3] Seong-Youp Suh, W. Stutzman, and W. Davis, "A new ultrawideband printed monopole antenna: the planar inverted cone antenna (PICA)," IEEE Transactions on Antennas and Propagation, vol. 52, 2004, pp. 1361-1364.

[4] Sachin Gupta, M Ramesh, and A. T. Kalghatgi, "Ultra Wideband Embedded Planar Inverted Conical Antenna," Microwave and Optical Technology Letters, vol. 48, 2006, pp. 2465-2468.

\section{Figures}

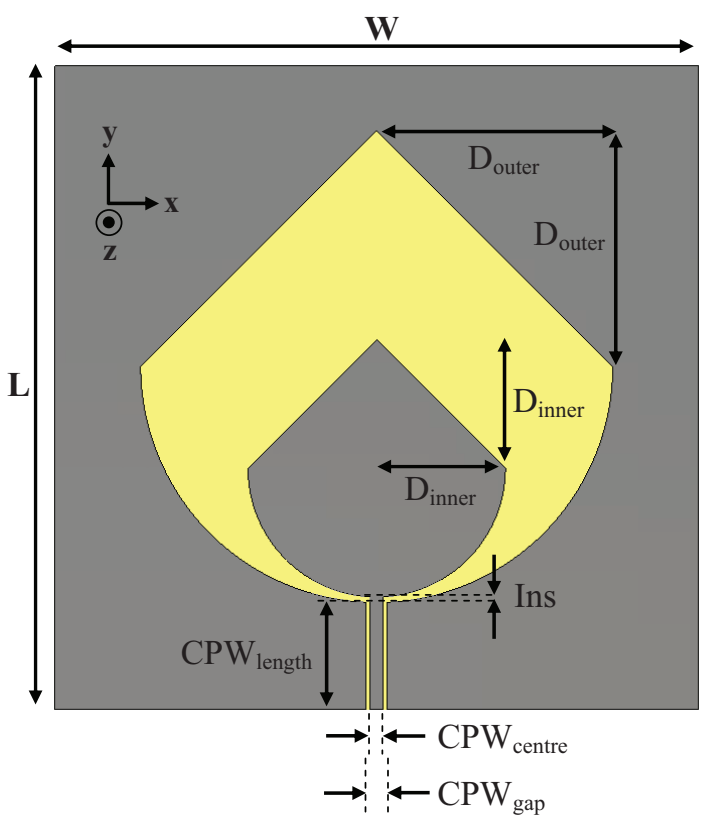

Figure 1. Geometry of the proposed CPW fed PICA slot antenna Parameters: $\mathrm{L}=120 \mathrm{~mm}, \mathrm{~W}=120 \mathrm{~mm}, \mathrm{CPW}_{\text {length }}=20 \mathrm{~mm}, \mathrm{CPW}_{\text {centre }}=2.44 \mathrm{~mm}$, $\mathrm{CPW}_{\text {gap }}=2.84 \mathrm{~mm}, \mathrm{D}_{\text {outer }}=44 \mathrm{~mm}, \mathrm{D}_{\text {inner }}=24 \mathrm{~mm}, \mathrm{Ins}=0.4 \mathrm{~mm}, \mathrm{~h}=0.8 \mathrm{~mm}$

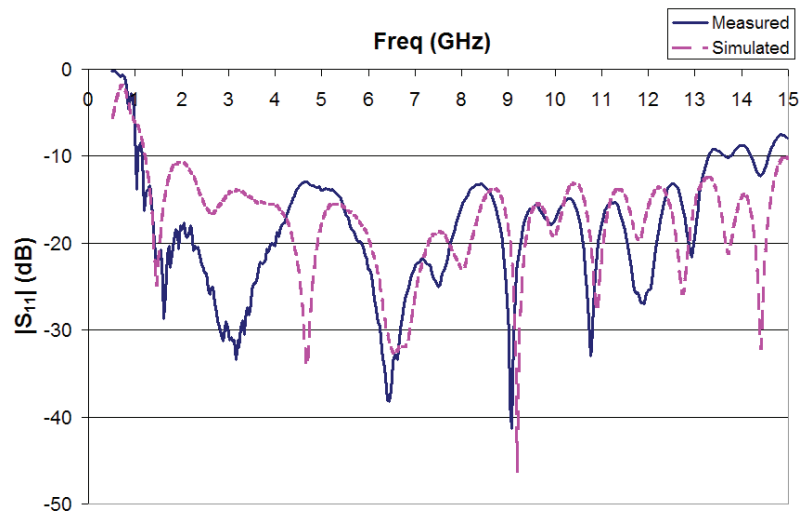

(a)

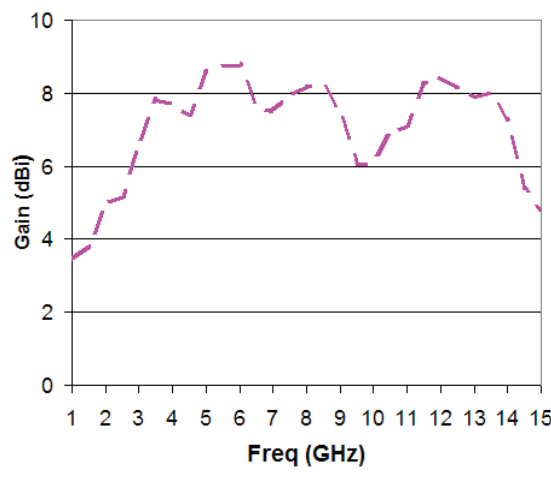

(b)

Figure 2. (a) Measured and simulated return loss of the CPW fed PICA slot antenna

(b) Simulated maximum gain vs frequency for the CPW fed PICA slot antenna 


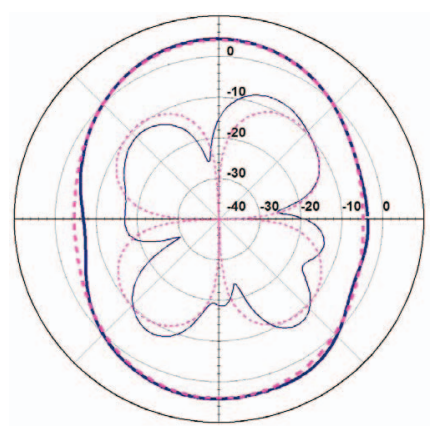

(a)
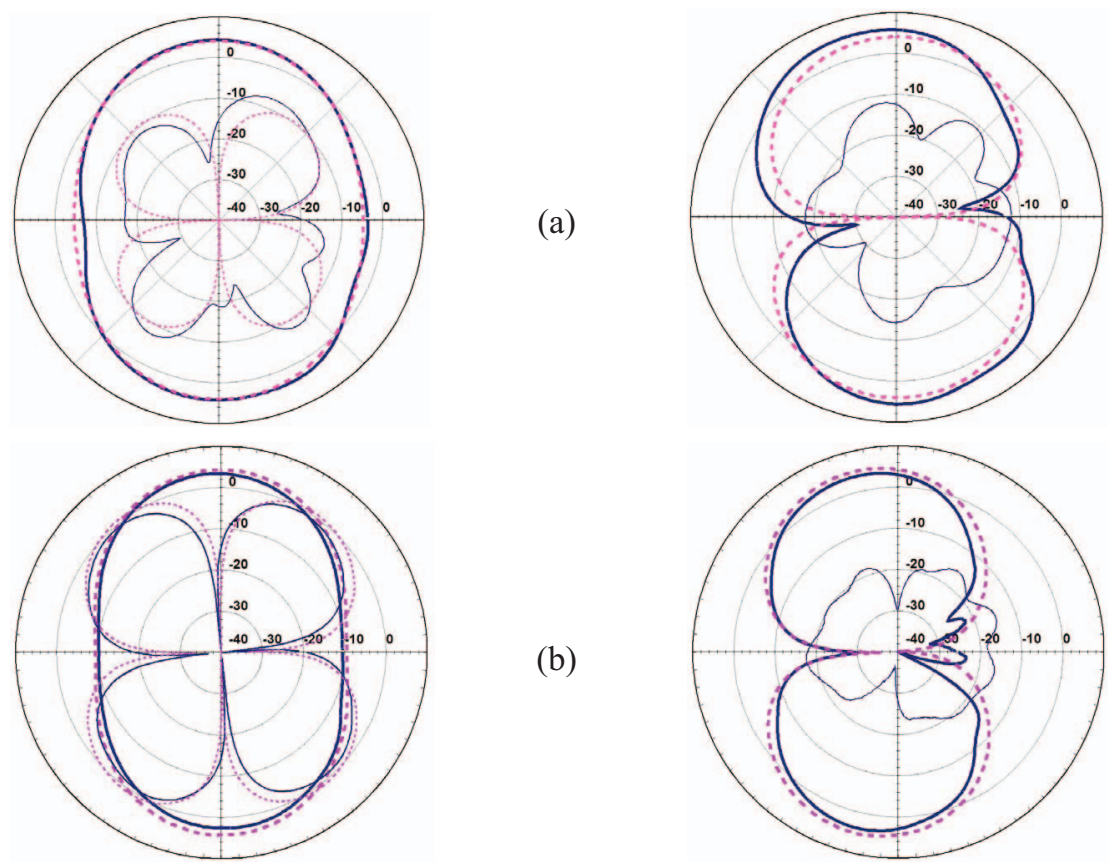

(b)
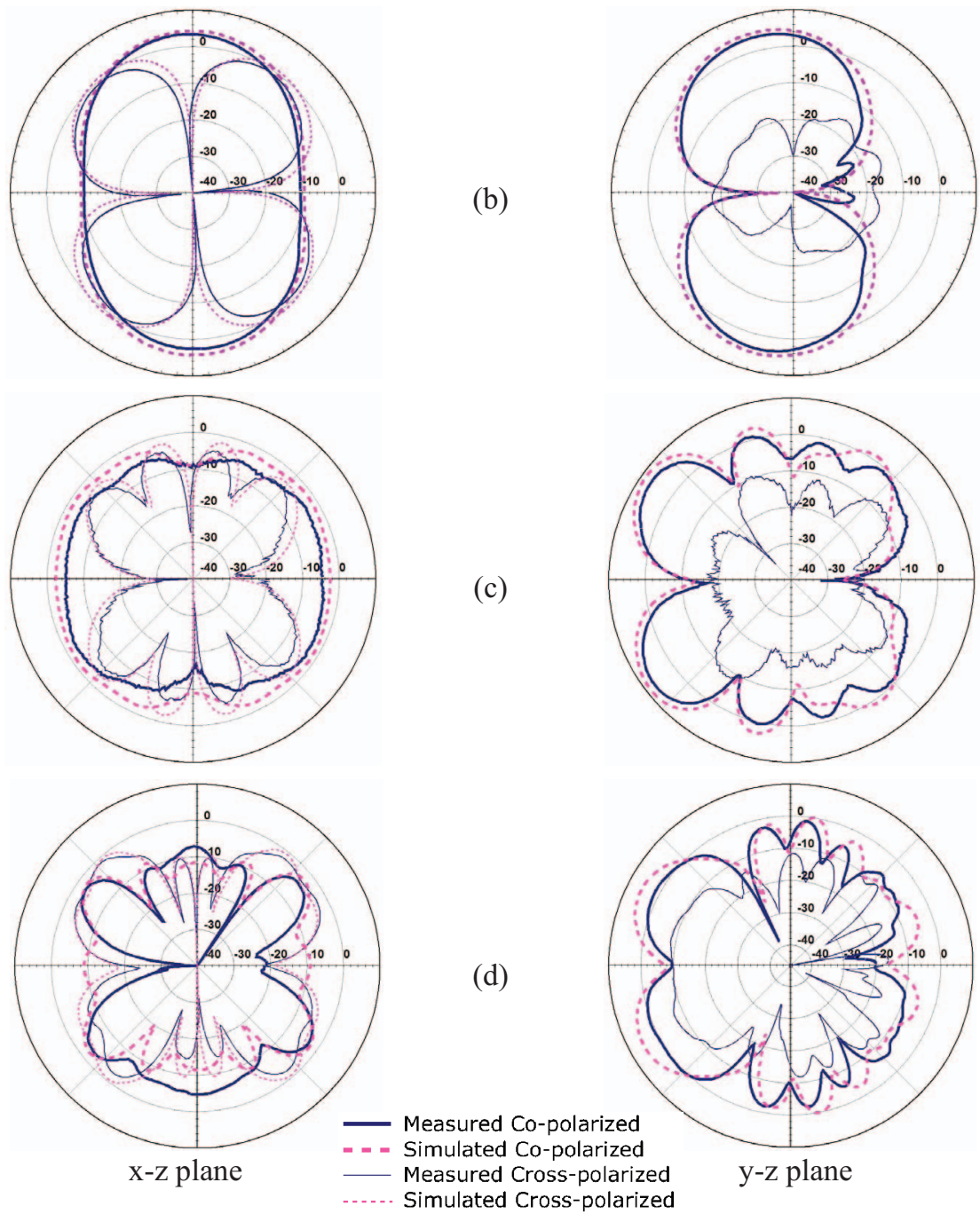

(c)

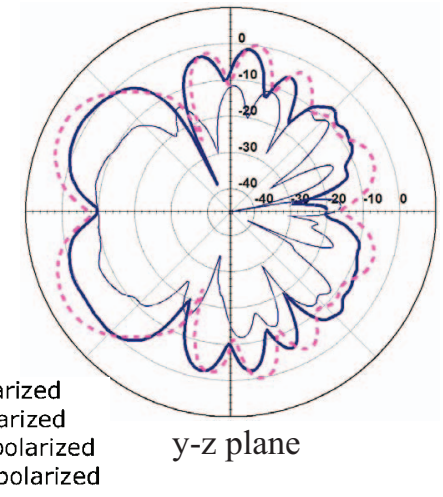

Figure 3. Far field radiation patterns of the CPW fed PICA slot antenna (a) $1.575 \mathrm{GHz}$ (b) $2.4 \mathrm{GHz}$ (c) $5.9 \mathrm{GHz}$ (d) $9.5 \mathrm{GHz}$

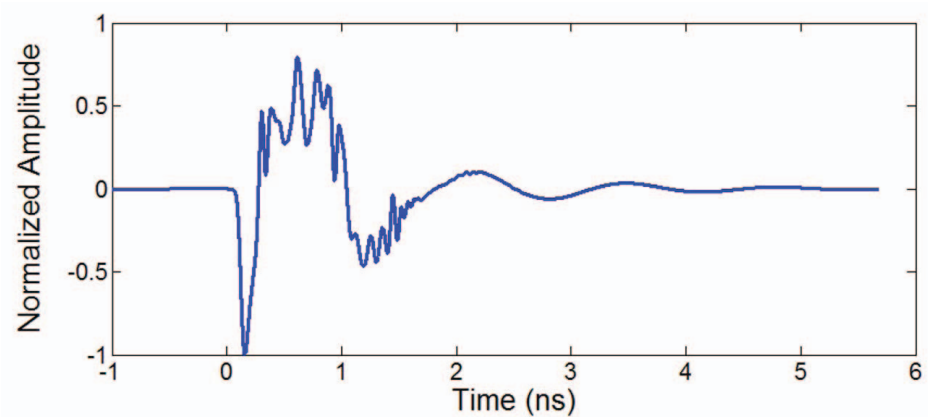

Figure 4. Simulated Impulse response of the CPW fed PICA slot antenna 